\title{
Effects of Topography on Seismic-Wave Propagation: An Example from Northern Taiwan
}

\author{
by Shiann-Jong Lee, Dimitri Komatitsch, ${ }^{*}$ Bor-Shouh Huang, and Jeroen Tromp ${ }^{\dagger}$
}

\begin{abstract}
Topography influences ground motion and, in general, increases the amplitude of shaking at mountain tops and ridges, whereas valleys have reduced ground motions, as is observed from data recorded during and after real earthquakes and from numerical simulations. However, recent publications have focused mainly on the implications for ground motion in the mountainous regions themselves, whereas the impact on surrounding low-lying areas has received less attention. Here, we develop a new spectral-element mesh implementation to accommodate realistic topography as well as the complex shape of the Taipei sedimentary basin, which is located close to the Central Mountain Range in northern Taiwan. Spectral-element numerical simulations indicate that high-resolution topography can change peak ground velocity (PGV) values in mountainous areas by $\pm 50 \%$ compared to a half-space response. We further demonstrate that large-scale topography can affect the propagation of seismic waves in nearby areas. For example, if a shallow earthquake occurs in the I-Lan region of Taiwan, the Central Mountain Range will significantly scatter the surface waves and will in turn reduce the amplitude of ground motion in the Taipei basin. However, as the hypocenter moves deeper, topography scatters body waves, which subsequently propagate as surface waves into the basin. These waves continue to interact with the basin and the surrounding mountains, finally resulting in complex amplification patterns in Taipei City, with an overall PGV increase of more than 50\%. For realistic subduction zone earthquake scenarios off the northeast coast of Taiwan, the effects of topography on ground motion in both the mountains and the Taipei basin vary and depend on the rupture process. The complex interactions that can occur between mountains and surrounding areas, especially sedimentary basins, illustrate the fact that topography should be taken into account when assessing seismic hazard.
\end{abstract}

\section{Introduction}

In the context of quantitative seismic hazard assessment, the Earth's surface is an important boundary that totally reflects upcoming seismic energy and produces surface waves. An irregular free surface can further lead to complex wave propagation. It has long been known that topography usually increases the amplitude of shaking at mountain tops and ridges, whereas valleys exhibit reduced ground motion, as is observed from records of past earthquakes (Hartzell et al., 1994; Spudich et al., 1996). In the last decade, numerical simulations have been successfully used to study the complex nature of ground motion due to earthquakes and the related seismic hazard (e.g., Olsen et al., 1995, 1996; Wald and Graves, 1998). Because of the difficulty of incorporating the

*Also at: Institut Universitaire de France, 103 boulevard Saint-Michel, 75005 Paris, France.

'Present address: Department of Geosciences, Princeton University, Princeton, New Jersey. free surface boundary condition in the finite-difference method in the presence of topography (see, for instance, Moczo et al., 2007), realistic topography was frequently not considered in simulations. Nevertheless, there have been a number of numerical investigations of the effects of topography on ground motion, including 2D calculations (see, for instance, Rulf, 1969; Fuyuki and Matsumoto, 1980; Wong, 1982; Geli et al., 1988; Kawase, 1988; Gaffet and Bouchon, 1989; Chiu and Huang, 1992; Bouchon and Barker, 1996) and 3D simulations (Frankel and Vidale, 1992; Luzon and Sânchez-Sesma, 1995; Bouchon et al., 1996; Komatitsch and Vilotte, 1998; Durand et al., 1999; Komatitsch et al., 2004). From these analyses we know more about topographic effects on seismic-wave propagation; however, the influence of topography on ground motion in surrounding low-lying areas, for example, nearby sedimentary basins, has received less attention. Lee et al. $(2008,2009)$ investigate $3 \mathrm{D}$ wave propagation in the Taipei metropolitan area using a 
spectral-element method (SEM) in combination with a realistic sedimentary basin model and free surface topography. Their results indicate that reflected and scattered waves originating in the mountains surrounding the Taipei basin cause longer ground shaking in both the mountains and the basin. For hypothetical large earthquake scenarios in southern California, Ma et al. (2007) suggest that, depending on the specific San Andreas segment that ruptures, the San Gabriel Mountains can partially shield Los Angeles from strong ground shaking.

In order to investigate the detailed interaction between large-scale topography and sedimentary basins, as well as the influence of source location, depth, and the rupture process on topographic effects, we study the Taipei basin and the Central Mountain Range (CMR) located in northern Taiwan (Fig. 1). Taipei City is situated on top of the Taipei sedimentary basin, which covers an area of about $20 \times 20 \mathrm{~km}$ and has a maximum depth of less than $1000 \mathrm{~m}$. The basin is surrounded by varied topography, including mountains, tableland, and a volcano group. Within these topographic structures, the CMR is dominant, running from southeast of the Taipei metropolitan area to southern Taiwan. It is the main range in Taiwan, with a total length of $340 \mathrm{~km}$ and con- sisting of mountains with elevations over $3000 \mathrm{~m}$. The highrise buildings of Taipei City, including Taipei 101, currently the tallest building in the world, located in the eastern part of the basin, make the heavily populated region particularly vulnerable to earthquakes. To investigate the effects of large-scale, realistic topography, that is, the CMR, on strong ground motion in Taipei City, we simulate an explosive point source located at the hypocenter of the 6 March 2005 I-Lan earthquake $\left(M_{\mathrm{L}} 5.9\right)$, which occurred about $60 \mathrm{~km}$ from Taipei City on the eastern side of the CMR. Using an explosion avoids effects due to source complexity, for example, the radiation pattern and finite-fault rupture. Next, keeping in mind that large subduction zone earthquakes can occur off the northeast coast of Taiwan, which can cause serious damage and which represents the largest earthquake potential hazard to Taipei City, we investigate several kinematic finite-fault rupture scenarios to estimate topographic effects on strong ground motion in the Taipei region for hypothetical subduction zone earthquakes.

It is worth mentioning that, if observed waveforms were available, they could probably help to motivate the study. But the Taiwan Strong Motion Instrumentation Program (TSMIP) stations in the CMR are sparse and do not provide enough
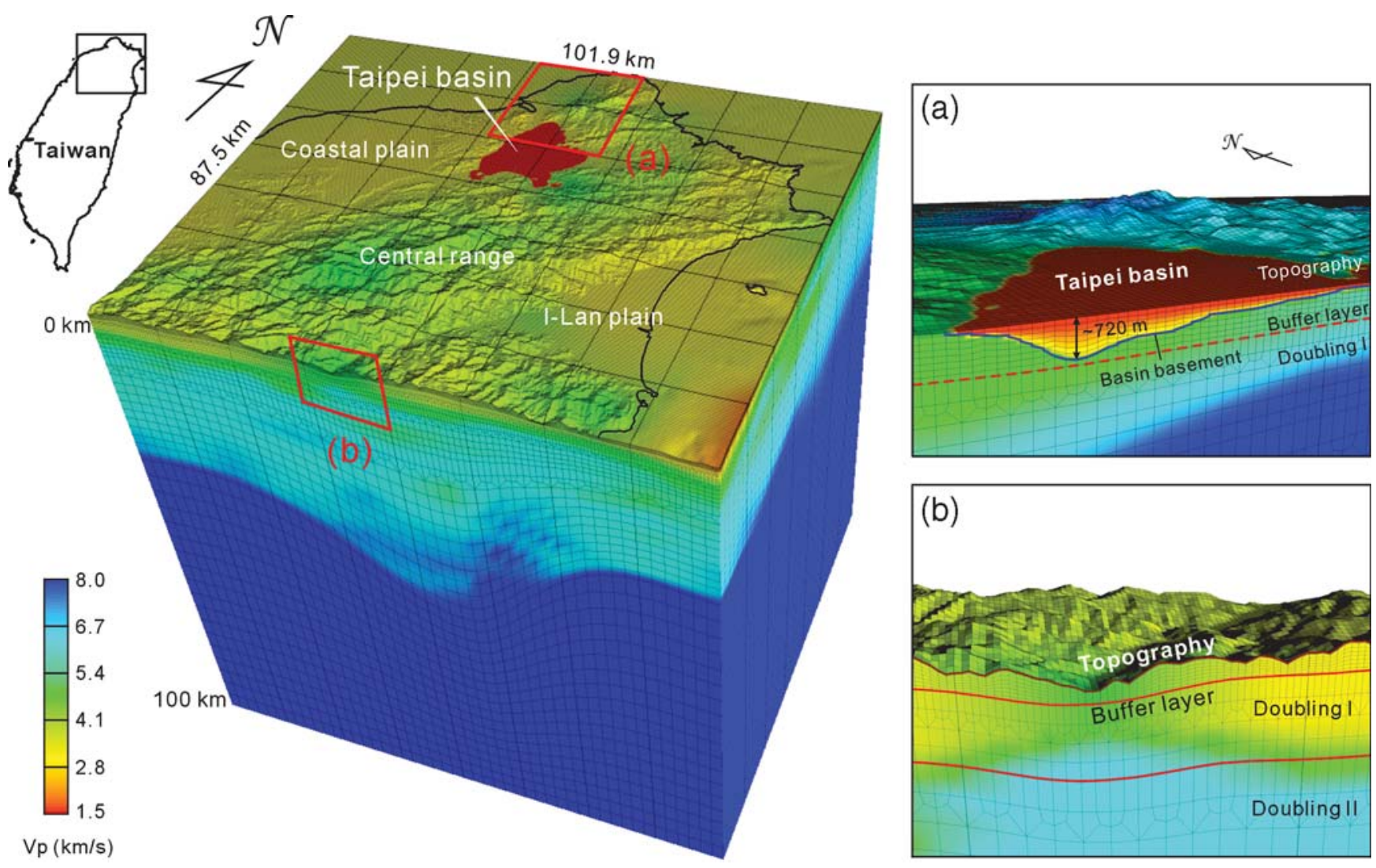

Figure 1. Spectral-element mesh for northern Taiwan. The size of the model is $101.9 \times 7.5 \mathrm{~km}$ horizontally and from +2.89 to $-100.0 \mathrm{~km}$ vertically. 3D $P$ wave-speed variations are represented by the rainbow color scale. The Taipei basin is located in the middle part of the model and is characterized by relatively low wave speeds compared to the surrounding areas. Two close-up views are shown in the panels to the right. (a) Mesh implementation for the Taipei basin. The basement of the basin is indicated by the blue line. (b) Mesh that incorporates realistic topography. A buffer layer is introduced to dampen mesh distortion due to steep topography. 
information to clarify the issue of topographic effects based on observations. Strong-motion stations are set in trigger mode; therefore, small earthquakes that occur in east Taiwan generally do not trigger stations in the Taipei basin. Larger earthquakes that occur in the I-Lan area could trigger more TSMIP stations in northern Taiwan, but their complex source process would make the analysis much more difficult (needing to distinguish between source effects and topographic effects). Although numerical simulations alone are not as powerful as simulations used in conjunction with real data, our results nonetheless provide interesting information of the influence of large-scale topography. These results can be meaningful also for future studies, such as planning wideangle land explosion surveys across Taiwan, designing new seismic networks in mountainous areas, or seismic hazard reduction studies in the Taipei metropolitan region.

\section{Realistic Topography and Basin Structure}

To accommodate the steep topography of the CMR as well as the highly variable low wave-speed sediments in the Taipei basin, we use SEM to simulate seismic-wave propagation in northern Taiwan. SEM is a numerical technique originally developed to address problems in computational fluid dynamics (Patera, 1984) and later adapted to simulate 3D seismic-wave propagation (see, for instance, Komatitsch and Vilotte, 1998; Komatitsch and Tromp, 1999). The method has been subsequently applied in many areas of seismology (e.g., Komatitsch et al., 2002; Chaljub et al., 2003; Komatitsch et al., 2004). A critical issue for the successful application of SEM lies in the design of a good mesh (e.g., Komatitsch et al., 2005). Lee et al. (2008) introduced a new mesh implementation using so-called control layers to improve mesh quality and the related numerical stability of the explicit time integration scheme. Based upon their implementation, realistic topography and complex subsurface structures can be efficiently incorporated in an SEM mesh.

The SEM mesh designed for this study is shown in Figure 1. Several control layers are located at different depths. The deepest one is the Moho, and the topography of the top of the model is defined based upon $40 \mathrm{~m}$ digital elevation model data. A buffer layer is implemented beneath the model surface and is used to dampen mesh distortions due to topography. This layer ensures that steep topography can be accommodated by the mesh without large distortion of the elements, which might cause numerical stability problems. In Figure $1 \mathrm{~b}$ we zoom in on the shallow part in the mountains to illustrate the effectiveness of this layer. It is clear that the buffer layer dampens most of the variations coming from the surface, which reduces mesh distortion due to steep topography, and, thus, realistic topography can be accommodated in the mesh without artificial smoothing. The 3D basin geometry and the related wave-speed model are taken from Wang et al. (2004). The slowest $P$ - and $S$-wave speeds in the basin are 1.5 and $0.2 \mathrm{~km} / \mathrm{sec}$, respectively. We embed the basin model in the regional tomographic model of Kim et al. (2005). The Taipei basin is introduced between the topography and a buffer layer. The mesh nodes that are located close to the basin basement are adjusted to redefine the basin boundary mesh and, therefore, honor the shape of the basin, as shown in Figure 1a. More details can be found in Lee et al. (2008).

\section{Topographic Effects for Point Sources}

We simulate the 3D wave field generated by an explosive source with a hypocenter determined by the 6 March 2005 I-Lan earthquake. The radiation pattern is, therefore, identical in all azimuths, which allows us to focus on the effects of topography alone. We use a Gaussian source time function with a half duration of $1 \mathrm{sec}$, and our mesh allows us to simulate the acceleration generated by the seismic waves up to a maximum frequency of $1 \mathrm{~Hz}$. To investigate the effects of large-scale topography, we consider two models: (1) a 3D wave-speed model with a sedimentary basin but without topography and (2) a 3D wave-speed model with both topography and a sedimentary basin. Snapshots of the surface wave field for both models are shown in Figure 2a and b, respectively. The model with topography produces a more complex wave field at the surface. Seismic waves are reflected and scattered when the waves travel through the mountains. In Figure $2 \mathrm{c}$ we subtract the velocity wave field without topography from that with topography to obtain the residual wave field. The residuals that accompany the body waves are due to slight body-wave delays in areas with topography. After the arrival of the body waves, the main residuals are found in the CMR and the I-Lan plain. This phenomenon is due to scattering of body waves by the irregular ground surface; these scattered waves are mostly surface waves.

In the right-hand panels of Figure 2 we show the distribution of peak ground velocity (PGV) in both models, computed using the norm of the velocity vector. In the flat model (Fig. 2a), most of the large PGV values occur in the I-Lan area closest to the epicenter. The Taipei basin shows relatively large PGV values compared to the surrounding regions due to the low wave-speed sediments in the basin. When topography is incorporated, complex PGV patches are found in the mountainous areas, especially in the CMR (Fig. 2b). Furthermore, the PGV values in the Taipei basin are amplified compared to the flat model. We use the PGV amplification factor to quantify the differences in PGV between the two models. It is obtained by subtracting the PGV value for the model without topography (Fig. 2a) from the value for the model with topography (Fig. 2b), dividing the result by the PGV value for the model without topography, and multiplying the result by 100 to obtain a percentage. Figure 2c illustrates that the PGV is increased at mountain tops and ridges, whereas valleys usually have a decreased PGV, that is, a negative PGV amplification factor. This phenomenon is also addressed by Lee et al. (2008, 2009), who analyze simulated ground motions in mountainous areas surrounding 


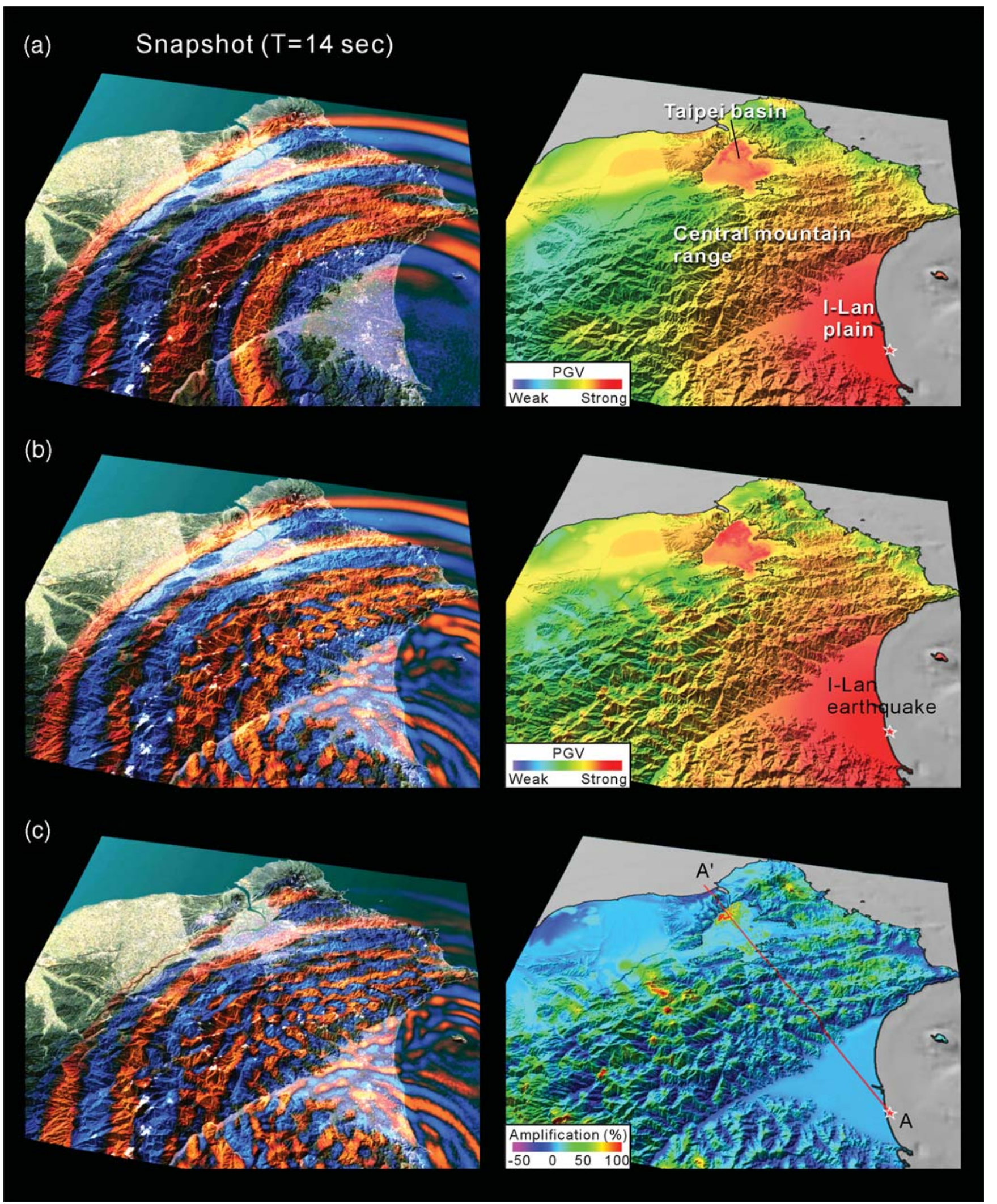

Figure 2. Snapshots of the wave field at the surface at $14 \mathrm{sec}$ and PGV determined for two models involving an explosive point source. (a) 3D wave-speed model with a basin but without topography; (b) 3D wave-speed model with both topography and the Taipei basin. (c) Residual wave field and PGV amplification determined for models (a) and (b). The PGV amplification factor is obtained by subtracting the PGV value for the model without topography from the value for the model with topography, dividing the result by the PGV value for the model without topography, and multiplying the result by 100 to obtain a percentage. 
the Taipei basin. In this study, we demonstrate that PGV values due to earthquakes occurring to the east of the CMR are further amplified in the areas of Taipei City located on top of the deepest parts of the basin.

Let us now analyze synthetic waveforms along profile $\mathrm{AA}^{\prime}$ shown in Figure 2 to see more quantitatively how waves are influenced by topography. Figure 3 shows the synthetic waveforms as well as the surface and subsurface structures along the profile. The synthetic seismograms become considerably more complex when topography is incorporated. Body waves do not exhibit an apparent change under the influence of topography, but there are several noticeable arrivals after the major body-wave arrivals. We subtract the synthetic waveforms for the model without topography from the waveforms for the model with topography to obtain the residuals. From the residual waveforms it is clear that the anomalous arrivals predominantly originate from the CMR, which reflects and scatters the body waves, which then spread outward as surface waves. These waves further interact with the basin and the surrounding mountains, resulting in a longer duration of shaking and more complex waveforms recorded at stations in Taipei City.

\section{Topographic Effects versus Source Depth}

We further investigate topographic effects on seismic waves in conjunction with variations in source depth by analyzing the relative change in PGV along profile $\mathrm{AA}^{\prime}$. We consider three different hypocenters: (1) $15 \mathrm{~km}$, (2) $40 \mathrm{~km}$, and (3) $2 \mathrm{~km}$. The resulting PGV amplifications are shown in Figure 4.

First, we analyze a hypocenter located in the middle crust at a depth of $15 \mathrm{~km}$ (Fig. 4a). The lower part of Figure 4a shows the PGV amplification distribution, which indicates that the PGV in mountainous areas increases at mountain tops and decreases in valleys. From the relative change in PGV along profile $\mathrm{AA}^{\prime}$ it is clear that the PGV amplification is only partly related to elevation. The variation in PGV is mainly controlled by gradients in topography, especially near mountain tops and in valleys, where the topographic gradient varies rapidly. It is notable that the PGV increases in most of the basin, especially in its western part, where the deepest basement is located. This is due to the fact that the waves reflect off the mountains and subsequently propagate as surface waves into the basin, resulting in constructive interference of the wave field, thereby increasing (a)
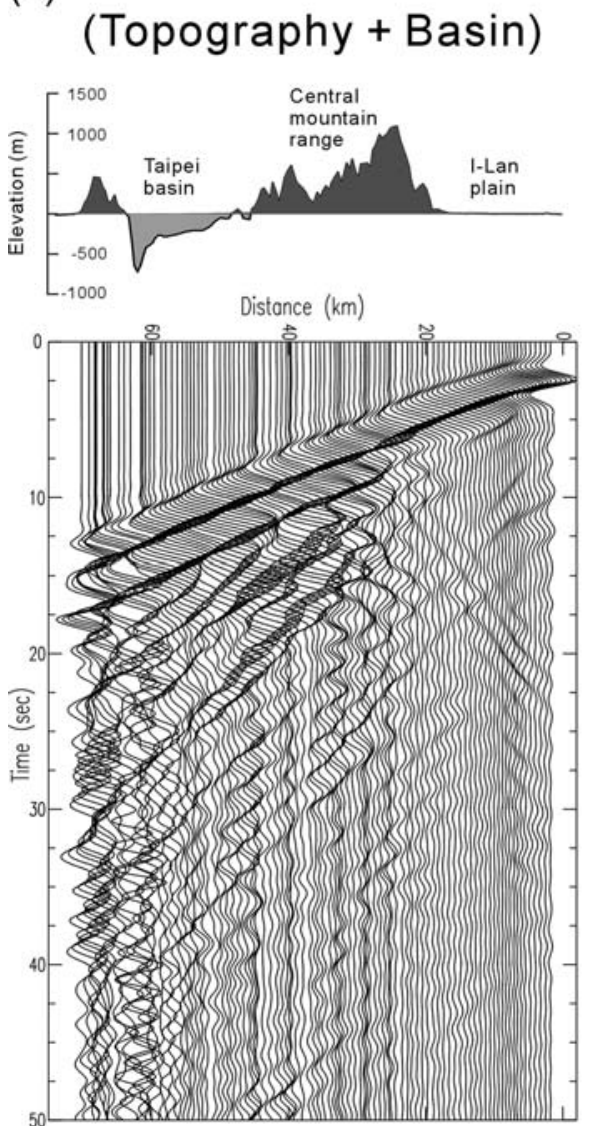

(b)
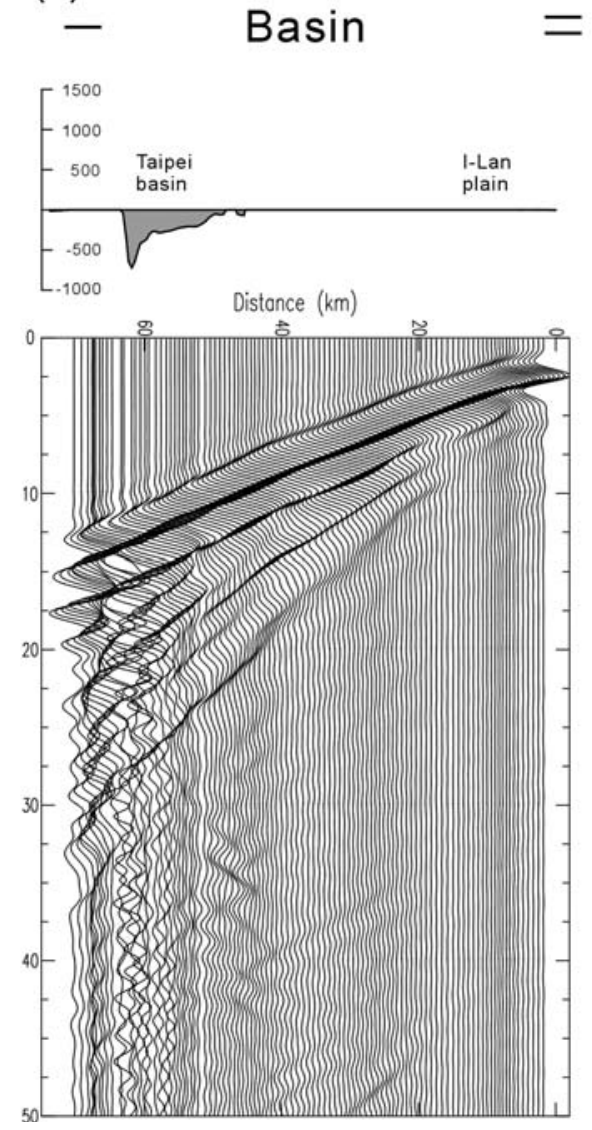

(c)
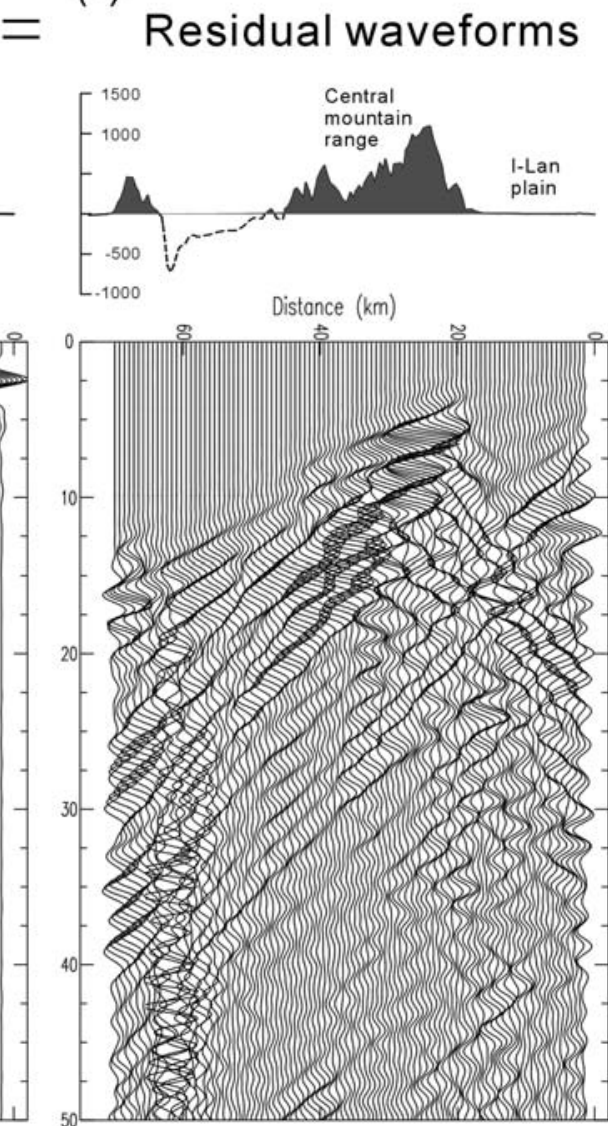

Figure 3. Synthetic waveforms along profile AA' in Figure 2c: (a) with topography, (b) without topography, and (c) residual waveforms computed by subtracting the synthetic seismograms without topography (b) from the synthetic seismograms with topography (a). The topography and subsurface structure along the profile are shown in the upper diagrams. 


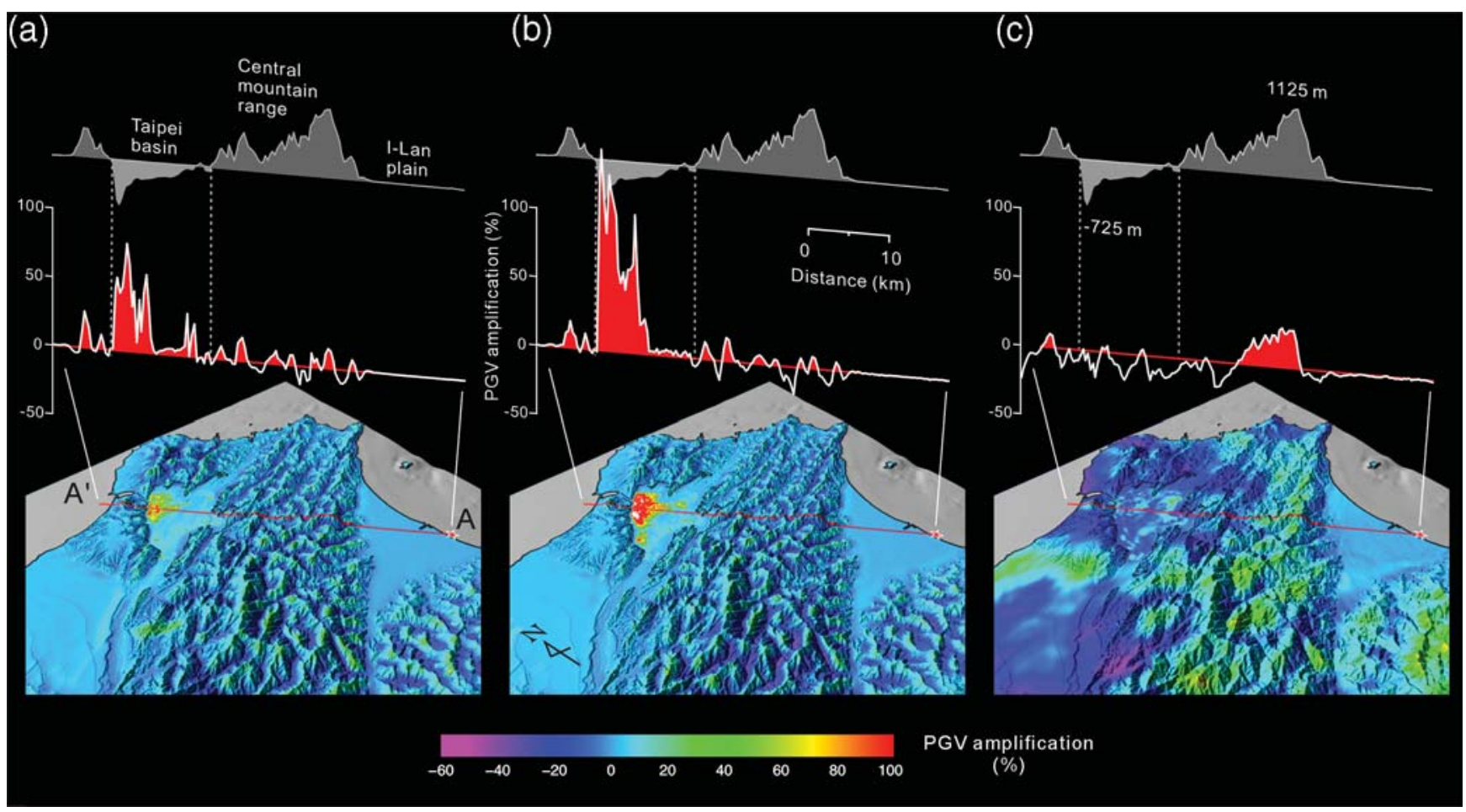

Figure 4. PGV amplification depending on source depth: (a) $15 \mathrm{~km}$, (b) $40 \mathrm{~km}$, and (c) $2 \mathrm{~km}$. The lower parts show the distribution of PGV amplification superimposed on topography. The upper diagrams show the topography, basin structure, and relative change in PGV along profile $\mathrm{AA}^{\prime}$.

the PGV in this part of Taipei. PGV amplification in most of the basin is greater than $+50 \%$ and in parts of the area approaches $+75 \%$, which is larger than what is observed in the mountainous areas, where the amplification is between $\pm 50 \%$ on average. When the hypocenter is located deeper, for example, at a depth of $40 \mathrm{~km}$, as shown in Figure $4 \mathrm{~b}$, the PGV amplification pattern in the mountains is similar to that determined for the $15 \mathrm{~km}$ deep event, that is, an increase at mountain tops and ridges and a reduction in valleys. The Taipei basin again exhibits increased PGV amplification, but the patches of amplification are concentrated and more pronounced in the western part of the basin, where the PGV values can be enhanced by more than $150 \%$.

When the hypocenter is shallow, for example, at $2 \mathrm{~km}$ depth, we find that the PGV decreases in most of the Taipei basin (Fig. 4c). For a shallow earthquake, the first arrivals are partly converted into surface waves in the I-Lan area. When these waves propagate into the CMR, they are significantly scattered by the topography, thereby reducing ground motion in the Taipei basin, which is located behind the CMR. It is remarkable that in the I-Lan area, even though the CMR reflects a lot of seismic energy back into the I-Lan plain (as shown in Fig. 2), PGV values are insignificantly affected for all three depth scenarios. This illustrates the fact that scattering is only one of the amplification factors and that interactions with local geology should also be taken into account. These results show that source depth modulates the effects of topography. Whether or not the CMR acts as a natural seismic insulator for Taipei City depends on the depth of the earthquake underneath the I-Lan area.

\section{Topographic Effects for Large Subduction Zone Earthquake Scenarios}

Large subduction zone earthquakes occurring offshore of northeastern Taiwan can cause serious seismic damage in Taipei City (Chen, 2003). It is, therefore, of interest to perform numerical simulations for realistic finite-fault earthquake scenarios occurring off the northeast coast of Taiwan and determine whether the PGV in the Taipei basin is reduced due to the CMR or not. On 31 March 2002, an $M_{\mathrm{w}} 7.0$ earthquake occurred in that area. It was the largest event in Taiwan since the 1999 Chi-Chi earthquake. Although the hypocentral distance to Taipei City was more than $100 \mathrm{~km}$, people in the city felt very strong and long-duration $(>30 \mathrm{sec})$ ground shaking. Seismic intensity in most parts of the city was larger than 5. This earthquake is, therefore, a good candidate to study large-scale topographic effects on ground motion in Taipei City for a rupture process in the subduction zone northeast of Taiwan. Unfortunately, the precise rupture process of this earthquake is not known due to poor inland station azimuthal coverage, which makes a source inversion study difficult to carry out. We, therefore, consider several hypothetical kinematic rupture scenarios to clarify whether large subduction zone earthquakes can produce an effect similar to what we observed for the shallow point source, 
that is, that the CMR reduces PGV values in Taipei, or similar to the deep point source, which induced increased PGV values in Taipei.

Based on the Global Centroid Moment Tensor (CMT) solution for the 31 March 2002 earthquake (see the Data and Resources section), we assume that these $M_{\mathrm{w}} 7.0$ subduction zone events rupture along a $51 \times 31 \mathrm{~km}$ northdipping fault plane, striking $291^{\circ}$ and dipping $32^{\circ}$. Four

\section{(a) Point source}

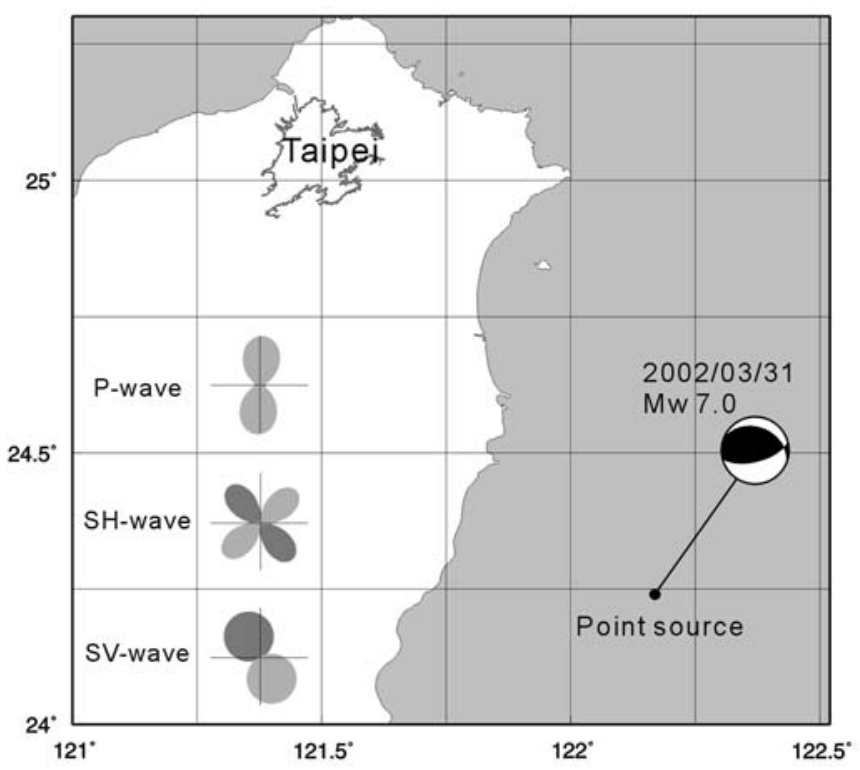

(c) Eastward rupture

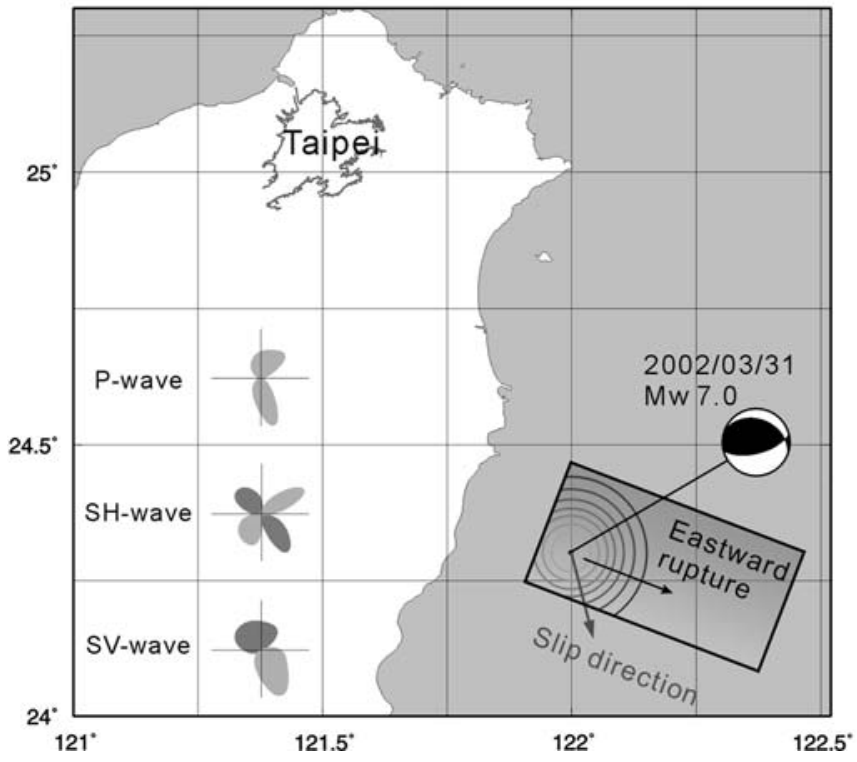

source scenarios are considered: (a) a double-couple point source, (b) a bilateral rupture, (c) an eastward rupture, and (d) a westward rupture (Fig. 5). For finite-fault rupture scenarios $\mathrm{b}, \mathrm{c}$, and $\mathrm{d}$, the fault plane is divided into 1581 subfaults (of size $1 \times 1 \mathrm{~km}$ ); the slip on the fault plane is considered uniform $(84 \mathrm{~cm})$ with a constant rake angle of $121^{\circ}$. The rupture velocity is assumed to be constant and to be equal to $2.5 \mathrm{~km} / \mathrm{sec}$. For each subfault we use a Gauss-

\section{(b) Bilateral rupture}

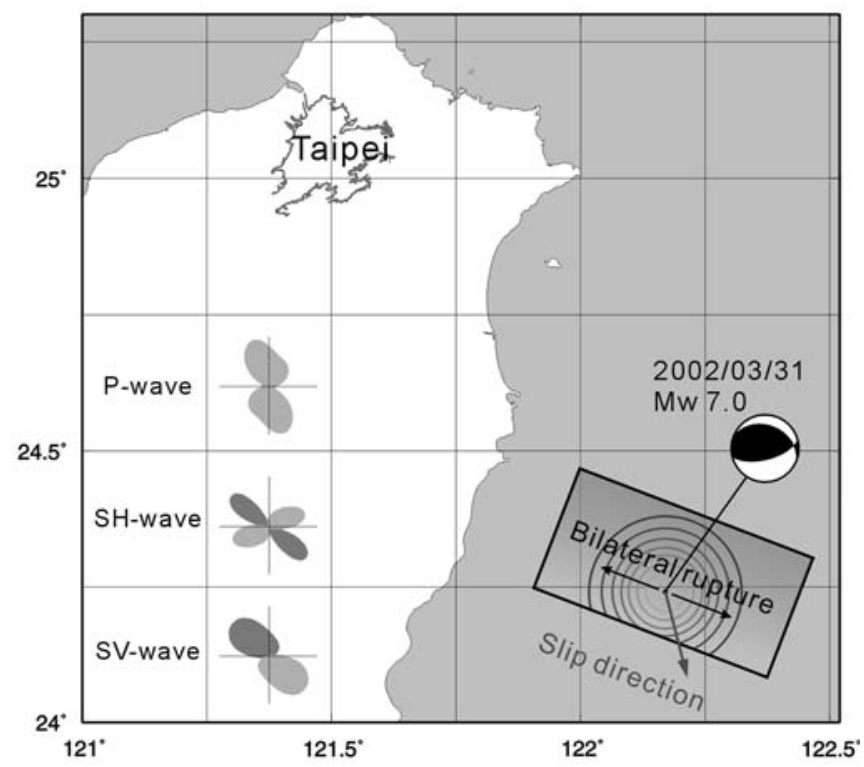

(d) Westward rupture

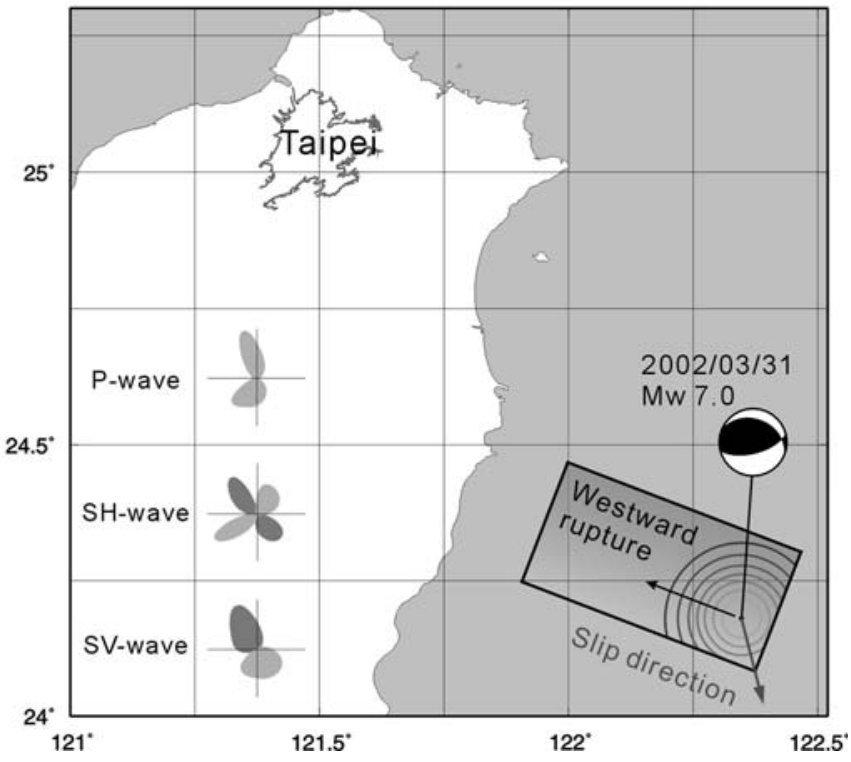

Figure 5. Four subduction zone earthquake rupture scenarios: (a) double-couple point source (at a depth of $18 \mathrm{~km}$ ), (b) bilateral rupture, (c) eastward rupture, and (d) westward rupture. The rupture area of the finite-fault source scenarios is a $51 \times 31 \mathrm{~km}$ north-dipping fault plane, striking $291^{\circ}$ and dipping $32^{\circ}$, which is based upon the CMT solution of a 31 March 2002 earthquake $\left(M_{\mathrm{w}} 7.0\right)$. The theoretical radiation patterns of $P, S H$, and $S V$ waves associated with the four source scenarios, assuming $V_{r} / V_{s}=0.8$, where $V_{r}$ is the rupture speed, are shown in the insets in the lower-left corner of the panels. 
ian source time function with a half duration of $1 \mathrm{sec}$. This source time function is also used in the case of the point source scenario a.

Snapshots of the vertical component of the velocity wave field for the four scenarios are displayed in Figure 6. In the case of the point source (Fig. 6a), waves are reflected and scattered when they propagate through the mountains. Ground motion in the Taipei basin is amplified and part of the seismic energy is trapped in the basin, which results in longer shaking. These results are similar to those discussed in the previous section for an explosive point source located under the I-Lan plain. However, the behavior is somewhat

(a) Point source
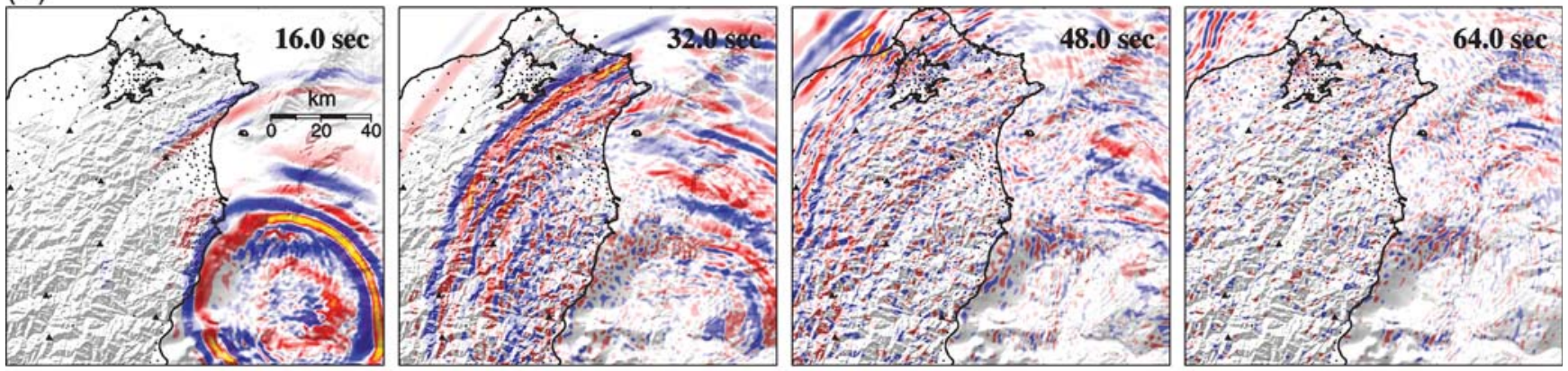

(b) Bilateral rupture
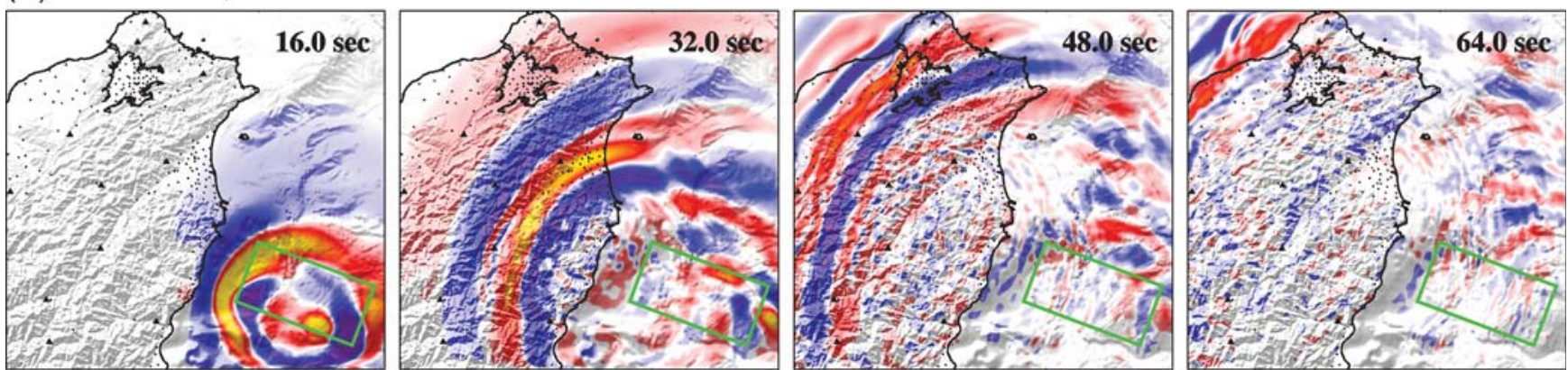

(c) Eastward rupture
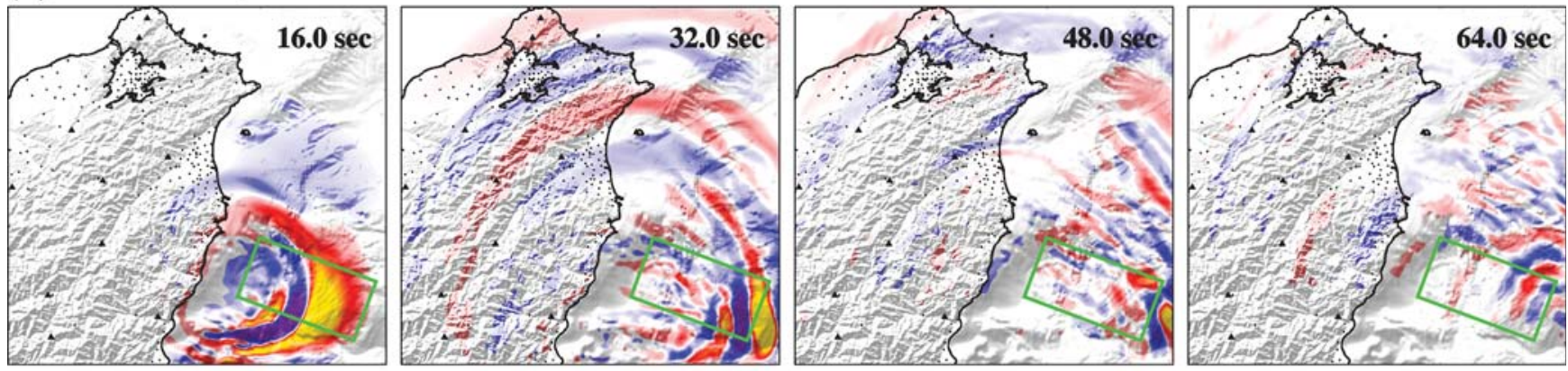

(d) Westward rupture
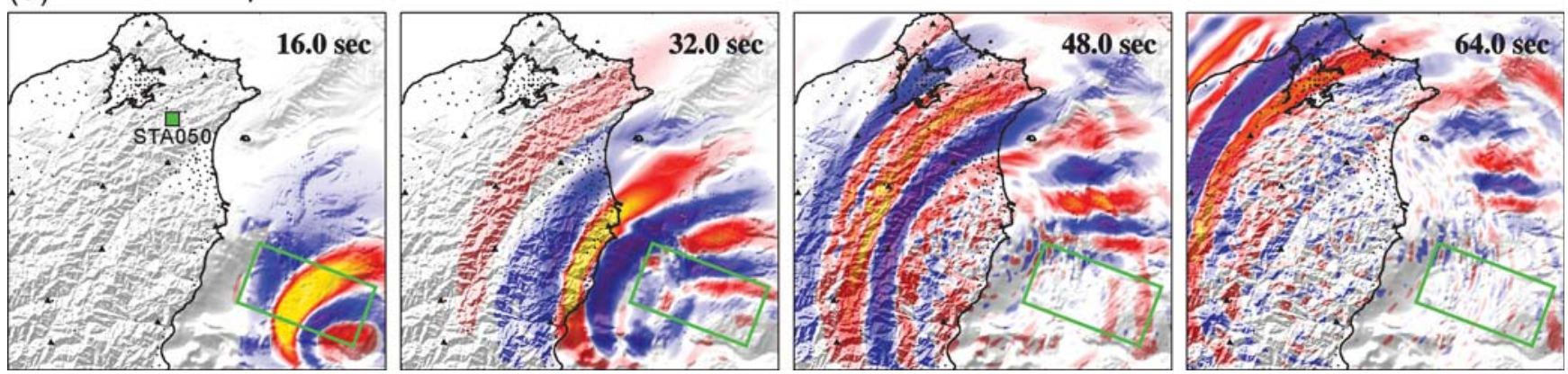

Figure 6. Snapshots of the vertical component of the velocity wave field for the four subduction zone rupture scenarios shown in Figure 5. Warm colors indicate a positive velocity and cold colors indicate a negative velocity. The amplitude in point source scenario (a) is divided by 15 compared to that in finite-fault rupture scenarios (b), (c), and (d). The open green rectangles show the rupture area in the case of the finitefault source scenarios. Station STA050 is denoted by the solid green square in the first panel of scenario (d). 
different in the case of the finite-fault bilateral rupture (Fig. 6b). Because of finite-fault rupture effects, seismic energy takes a longer time to be released from the fault plane. Even though the source time function on each subfault is the same as that used in the point source scenario a, the finitefault rupture results in lower frequency seismic waves and, therefore, longer-period ground motion. Mountain reflections and basin amplification are still observed for these long-period ground motions, but their strength is decreased. When rupture is unilateral, for example, eastward (Fig. 6c) or westward (Fig. 6d), the wave field is dominated by directivity effects. In the case of eastward rupture, most of the seismic waves propagate toward the Pacific Ocean and ground motion in Taipei is relatively weak. But in the case of westward rupture, ground motion becomes much larger due to directivity effects. In this case, northern Taiwan suffers the strongest ground motion, as well as the longest shaking, compared to the other two finite-fault rupture scenarios. Examples of synthetic waveforms recorded at a fictitious seismic station located in the CMR that we will call STA050 are shown in Figure 7. For the vertical component of velocity in the case of the point source (Fig. 7a), the $P$ wave, $S V$ wave, and later reflections can be clearly identified. The frequency spectra indicate that the dominant frequency is about $0.3 \mathrm{~Hz}$, that is, slightly lower than the source frequency of $0.5 \mathrm{~Hz}$. The synthetic seismograms computed for the finite-fault rup- tures (Fig. 7b, c, and d) exhibit longer-period waveforms. Their respective frequency spectra indicate that the dominant frequency is about $0.1 \mathrm{~Hz}$, which is far lower than the original source frequency of each subfault. Again, this is due to the kinematic rupture, which results in longer-period waves. In these finite-rupture scenarios, the $P, S V$, and later arrivals, such as the waves reflected off the mountains, are not readily identified.

To quantify the effects of topography for different source scenarios, let us analyze the PGV amplification factor along a profile across the CMR and the Taipei basin (Fig. 8). The result for the double-couple point source a is similar to that obtained previously for an explosion source at a depth of $15 \mathrm{~km}$ (Fig. 4a). This indicates that parts of the Taipei basin have amplification values that are close to $+75 \%$, which is larger than what is observed in the mountainous areas, where the amplification is $\pm 50 \%$ on average. For scenario $\mathrm{b}$ involving a bilateral rupture, the PGV amplification increases in most of the basin, but mountainous areas do not exhibit significant changes. In the case of eastward rupture, PGV values exhibit a large increase in mountainous areas. Eastern Taipei and the area located on top of the deepest part of the basin show positive PGV amplification. In this rupture scenario, it looks like the CMR scatters parts of the seismic waves, thereby reducing ground motion in some areas of the Taipei basin. But in the case of westward rupture, it is
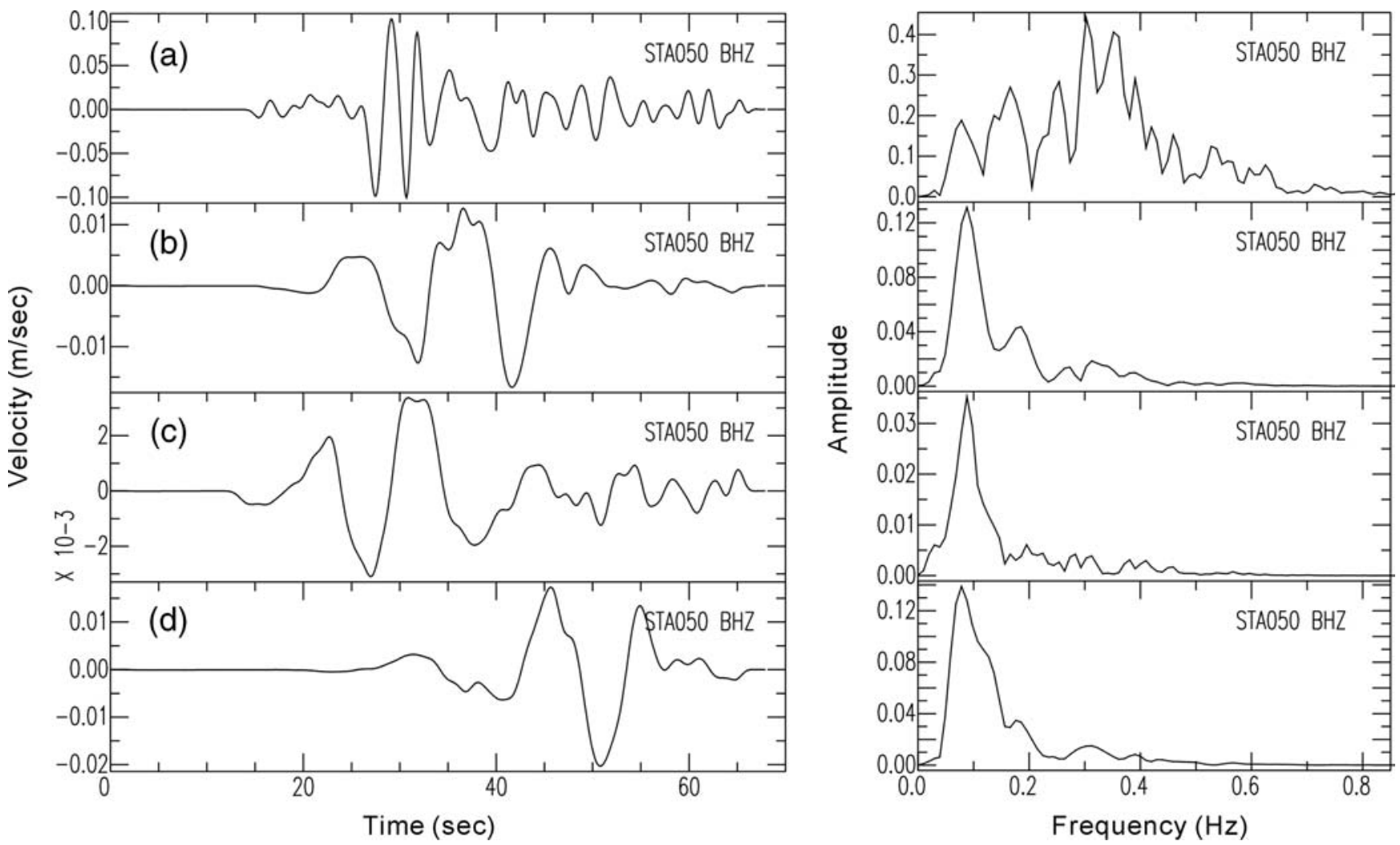

Figure 7. Synthetic waveforms and frequency spectra computed at station STA050 (solid green square in the first panel in Fig. 6d) for the four subduction zone rupture scenarios shown in Figure 5. The left-hand diagrams show the vertical component synthetic waveforms, and the right-hand diagrams are the corresponding frequency spectra. 


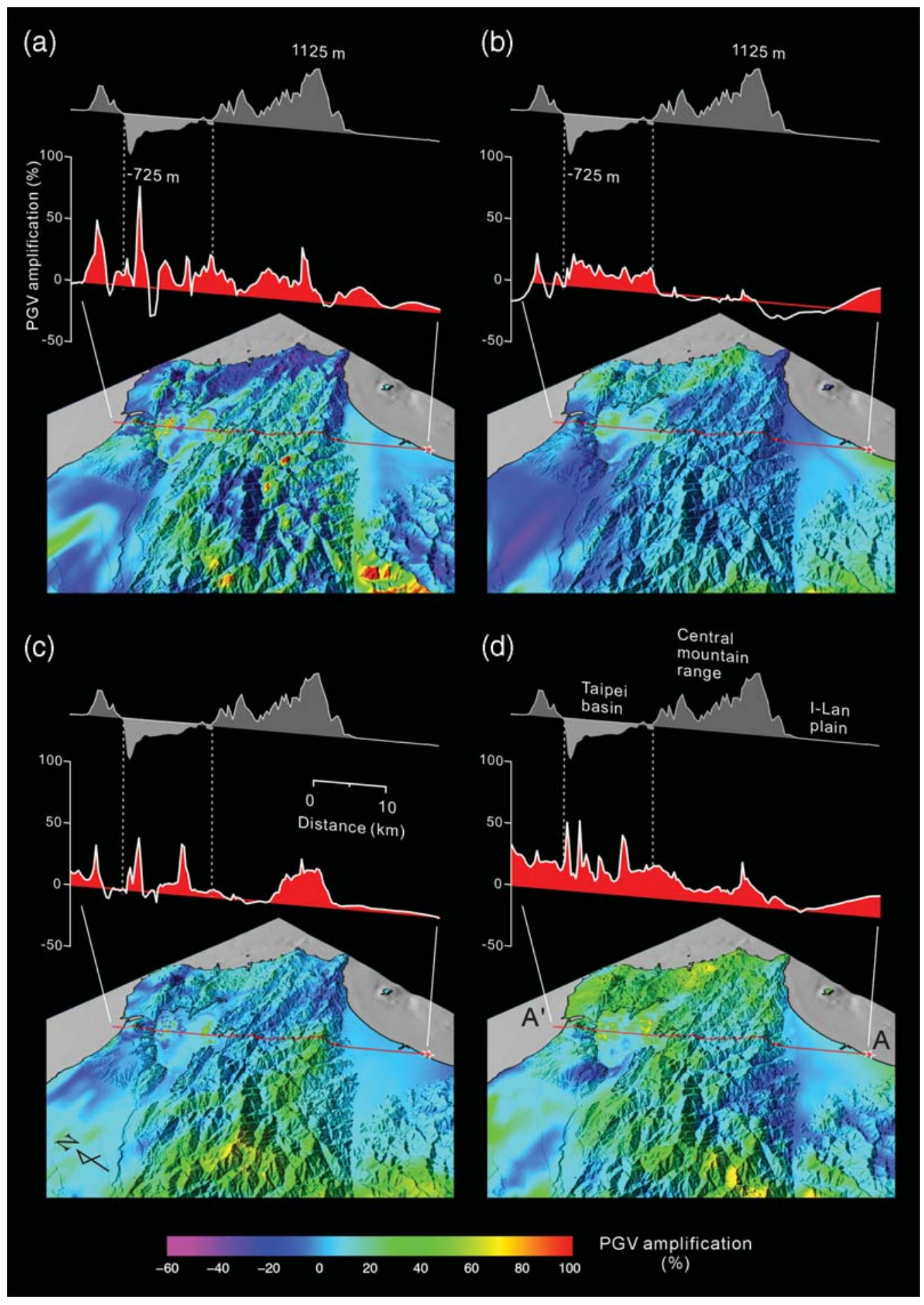

Figure 8. PGV amplification computed for the four subduction zone rupture scenarios shown in Figure 5: (a) point source, (b) bilateral rupture, (c) eastward rupture, and (d) westward rupture. The lower parts in each panel show the distribution of PGV amplification superimposed on topography. The upper diagrams in each panel show the topography, basin structure, and relative change in PGV along profile AA'.

notable that the PGV amplification values increase almost everywhere. The average value is about $+30 \%$, and some areas in the Taipei basin exhibit values close to $+50 \%$. The CMR no longer acts as a seismic insulator for Taipei City when the rupture propagates toward Taiwan.

\section{Conclusions}

We investigated the effects of large-scale topography associated with the CMR in northern Taiwan on strong ground motion in the Taipei basin due to earthquakes occurring in 
the I-Lan region east of the CMR and also due to subduction zone earthquake scenarios occurring off the northeast coast of Taiwan. A carefully designed mesh was used to accommodate steep topography and the complex geometry of the Taipei basin. Our numerical simulations, performed based upon SEM, demonstrate that high-resolution topography can change PGV values in mountainous areas by $\pm 50 \%$ compared to the response of a half-space. We also show that variations in source depth modulate the influence of topography on ground motion in neighboring low-lying areas. If a shallow earthquake occurs in the I-Lan region, we find that the CMR significantly scatters the surface waves and, therefore, reduces ground motion in the Taipei basin. However, when we move the hypocenter deeper, topography scatters the body waves, which subsequently propagate as surface waves and spread into the Taipei basin. These waves further interact with the basin and the surrounding mountains, finally resulting in complex amplification patterns $(>50 \%)$ in Taipei City.

We have also investigated several hypothetical rupture scenarios of subduction zone earthquakes occurring off the northeast coast of Taiwan. Although the rupture scenarios considered in this study are relatively simple compared to a real earthquake, which would need to include asperities, a varying rise time along the fault plane, and a varying rupture velocity, we have shown that the effects of topography on ground motion vary depending on the source rupture process. Our simulations show that topography has different effects depending on the scenario: it may or may not reduce ground motion in Taipei depending on the directivity, location, and depth of the event. These results illustrate the fact that topography should be taken into account when assessing seismic hazard.

\section{Data and Resources}

We used the SPECFEM3D software package (www .geodynamics.org, last accessed November 2008) developed by Komatitsch et al. (2004) in this study. Some plots were made using the Persistence of Vision Raytracer (www .povray.org, last accessed November 2008). The Global Centroid Moment Tensor Project database was searched using www.globalcmt.org/CMTsearch.html (last accessed November 2008).

\section{Acknowledgments}

This research represents a collaborative effort between the California Institute of Technology (Caltech), Institute of Earth Sciences Academia Sinica (IESAS), National Central University (NCU), and the University of Pau. The authors thank J.-H. Wang, S.-B. Yu, and J.-P. Avouac for making this collaboration possible. Special thanks go to IESAS and the Caltech Seismological Laboratory, where many fruitful discussions occurred. The simulations were carried out on the Division of Geological and Planetary Sciences Dell cluster at Caltech. This research was supported in part by the Academia Sinica, Taiwan, under Grant Number AS-94-TP-A08 and the U.S. National Science Foundation under Grant Number 0711177. This is Contribution Number 8994 of the Division of Geological and Planetary Sciences, California Institute of Technology.

\section{References}

Bouchon, M., and J. S. Barker (1996). Seismic response of a hill: the example of Tarzana, California, Bull. Seismol. Soc. Am. 86, 66-72.

Bouchon, M., C. Schultz, and M. Toksoz (1996). Effect of three-dimensional topography on seismic motion, J. Geophys. Res. 101, 5835-5846.

Chaljub, E., Y. Capdeville, and J. P. Vilotte (2003). Solving elastodynamics in a fluid-solid heterogeneous sphere: a parallel spectral element approximation on non-conforming grids, J. Comput. Phys. 187, no. 2, 457-491.

Chen, K. C. (2003). Strong ground motion and damage in the Taipei basin from the Moho reflected seismic waves during the March 31, 2002, Hualien, Taiwan earthquake, Geophys. Res. Lett. 30, no. 11, 1551, doi 10.1029/2003GL017193.

Chiu, H. C., and H. C. Huang (1992). Effects of the canyon topography on ground motions at the Feitsui dam site, Bull. Seismol. Soc. Am. 82, no. $4,1646-1660$.

Durand, S., S. Gaffet, and J. Virieux (1999). Seismic diffracted waves from topography using 3D discrete wavenumber-boundary integral equation simulations, Geophysics 64, 572-578.

Frankel, A., and J. Vidale (1992). A three-dimensional simulation of seismic waves in the Santa Clara Valley, California, from a Loma Prieta aftershock, Bull. Seismol. Soc. Am. 82, 2045-2074.

Fuyuki, M., and Y. Matsumoto (1980). Finite difference analysis of Rayleigh wave scattering at a trench, Bull. Seismol. Soc. Am 70, 2051-2069.

Gaffet, S., and M. Bouchon (1989). Effects of two-dimensional topographies using the discrete wavenumber-boundary integral equation method in P-SV cases, J. Acoust. Soc. Am. 85, 2277-2283.

Geli, L., P.-Y. Bard, and B. Jullen (1988). The effect of topography on earthquake ground motion: a review and new results, Bull. Seismol. Soc. Am. 78, 42-63.

Hartzell, S. H., D. L. Carver, and K. W. King (1994). Initial investigation of site and topographic effects at Robinwood Ridge, California, Bull. Seismol. Soc. Am. 84, 1336-1349.

Kawase, H. (1988). Time-domain response of a semi-circular canyon for incident $S V, P$, and Rayleigh waves calculated by the discrete wavenumber boundary element method, Bull. Seismol. Soc. Am. 78, 1415-1437.

Kim, K. H., J. M. Chiu, J. Pujol, K. C. Chen, B. S. Huang, Y. H. Yeh, and P. Shen (2005). Three-dimensional $V_{P}$ and $V_{S}$ structural models associated with the active subduction and collision tectonics in the Taiwan region, Geophys. J. Int. 162, 204-220.

Komatitsch, D., and J. Tromp (1999). Introduction to the spectral-element method for 3-D seismic wave propagation, Geophys. J. Int. 139, 806-822.

Komatitsch, D., and J. P. Vilotte (1998). The spectral-element method: an efficient tool to simulate the seismic response of 2D and 3D geological structures, Bull. Seismol. Soc. Am. 88, no. 2, 368-392.

Komatitsch, D., Q. Liu, J. Tromp, P. Süss, C. Stidham, and J. H. Shaw (2004). Simulations of ground motion in the Los Angeles basin based upon the spectral-element method, Bull. Seismol. Soc. Am. 94, 187-206.

Komatitsch, D., J. Ritsema, and J. Tromp (2002). The spectral-element method, Beowulf computing, and global seismology, Science 298, 1737-1742.

Komatitsch, D., S. Tsuboi, and J. Tromp (2005). The spectral-element method in seismology, in Seismic Earth: Array Analysis of Broadband Seismograms, A. Levander and G. Nolet (Editors), American Geophysical Monograph, 157, 205-227.

Lee, S. J., Y. C. Chan, D. Komatitsch, B. S. Huang, and J. Tromp (2009). Effects of realistic surface topography on seismic ground motion in the Yangminshan region (Taiwan) based upon the Spectral-Element Method and LiDAR DTM, Bull. Seismol. Soc. Am. (in press).

Lee, S. J., H. W. Chen, Q. Liu, D. Komatitsch, B. S. Huang, and J. Tromp (2008). Three-dimensional simulations of seismic wave propagation in the Taipei basin with realistic topography based upon the spectral- 
element method, Bull. Seismol. Soc. Am. 98, 253-264, doi 10.1785/ 0120070033.

Luzon, E., and F. Sânchez-Sesma (1995). Seismic response of three dimensional topographies, Int. J. Soil Dyn. Earthq. Eng. 1-14.

Ma, S., R. J. Archuleta, and M. T. Page (2007). Effects of large-scale surface topography on ground motions, as demonstrated by a study of the San Gabriel Mountains, Los Angeles, California, Bull. Seismol. Soc. Am. 97, 2066-2079, doi 10.1785/0120070040.

Moczo, P., J. Robertsson, and L. Eisner (2007). The finite-difference timedomain method for modeling of seismic wave propagation, $A d v$. Wave Propag. Heterog. Earth 48, 421-516.

Olsen, K. B., R. J. Archuleta, and J. R. Matarese (1995). Three-dimensional simulation of a magnitude 7.75 earthquake on the San Andreas fault, Science 270, 1628-1632.

Olsen, K. B., J. C. Pechmann, and G. T. Schuster (1996). An analysis of simulated and observed blast records in the Salt Lake basin, Bull. Seismol. Soc. Am. 86, 1061-1076.

Patera, A. T. (1984). A spectral element method for fluid dynamics: laminar flow in a channel expansion, J. Comput. Phys. 54, 468-488.

Rulf, B. (1969). Rayleigh waves on curved surfaces, J. Acoust. Soc. Am. 45, 493-499.

Spudich, P., M. Hellweg, and W. H. K. Lee (1996). Directional topographic site response at Tarzana observed in aftershocks of the 1994 Northridge, California, earthquake: implications for mainshock motions, Bull. Seismol. Soc. Am. 86, no. 1B, S193-S208.

Wald, D. J., and R. W. Graves (1998). The seismic response of the Los Angeles basin, California, Bull. Seismol. Soc. Am. 88, 337-356.
Wang, C. Y., Y. H. Lee, M. L. Ger, and Y. L. Chen (2004). Investigating subsurface structures and $\mathrm{P}$ - and $\mathrm{S}$-wave velocities in the Taipei basin, Terr. Atmos. Ocean. Sci. 15, 222-250.

Wong, H. L. (1982). Effect of surface topography on the diffraction of $P, S V$, and Rayleigh waves, Bull. Seismol. Soc. Am. 72, 1167-1183.

Institute of Earth Sciences

Academia Sinica

Nankang, Taipei 115 Taiwan

sjlee@earth.sinica.edu.tw

hwbs@earth.sinica.edu.tw

(S.-J.L., B.-S.H.)

Department of Geophysical Modeling and Imaging in Geosciences, CNRS UMR 5212 and INRIA Magique 3D

University of Pau

64013 Pau Cedex, France

dimitri.komatitsch@univ-pau.fr

(D.K.)

Seismological Laboratory

California Institute of Technology

Pasadena, California 91125

(J.T.)

Manuscript received 3 April 2008 